\title{
ChemComm
}

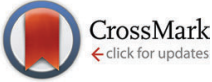

Cite this: Chem. Commun., 2016, 52,8247

Received 16th May 2016 Accepted 5th June 2016

DOI: $10.1039 / \mathrm{c} 6 \mathrm{cc} 04100 \mathrm{k}$

www.rsc.org/chemcomm

\section{A BODIPY-based fluorescent probe for ratiometric detection of gold ions: utilization of Z-enynol as the reactive unit $\dagger$}

\author{
Muhammed Üçüncü, Erman Karakuş and Mustafa Emrullahoğlu*
}

\begin{abstract}
Using an irreversible intramolecular cyclisation pathway triggered by gold ions, a boron-dipyrromethene (BODIPY) based fluorescent probe integrated with a reactive $Z$-enynol motif responds selectively to gold ions. With the addition of gold(III), the probe displays ratiometric fluorescence behaviour clearly observable to the naked eye under both visible and UV light.
\end{abstract}

Though primarily known for its monetary value, gold has recently attracted attention for its impressive catalytic features as well. In synthetic chemistry, the use of gold species has opened new avenues in the synthesis of complex molecular structures. ${ }^{1}$ However, the increasing use of gold species in chemical synthesis is concomitantly raising hard-to-ignore health and environmental risks due to their potential toxicity. The intake of gold ions in living systems has been widely found to damage vital human organs, including the kidney and liver, as well as the peripheral nervous system. ${ }^{2}$ It is therefore crucial for the scientific community to be able to assess the levels of gold species in certain chemical, environmental, and biological matrices.

In that context, research continues to focus on developing analytical tools for probing gold species, among which fluorescentbased assays have attracted particular attention for allowing the real-time visualisation of target species in cellular milieus. In recent years, numerous types of fluorescent gold ion probes have appeared in literature on the topic, most of which involve using specific chemical reactions to exploit the alkynophilic nature of gold ions. ${ }^{3}$ By extension, various fluorescent moleculesrhodamine, ${ }^{4}$ boron-dipyrromethene (BODIPY), ${ }^{5}$ fluorescein, ${ }^{6}$ and naphthalimide ${ }^{7}$ - have been used as signal-reporting fluorophores to recognise gold species by colorimetric or fluorometric changes, if not both, in which optical output is usually recognised as an increase in or activation of emission intensity. However, measurements based on intensity changes are easily

Department of Chemistry, Faculty of Science, Izmir Institute of Technology, Urla, 35430, Izmir, Turkey. E-mail: mustafaemrullahoglu@iyte.edu.tr $\dagger$ Electronic supplementary information (ESI) available: Absorbance and fluorescence data and all experimental procedures. See DOI: 10.1039/c6cc04100k influenced by a host of environmental factors, including concentration variations, photo-bleaching, and excitation intensity.

To overcome the barriers generally associated with intensitybased sensors, measuring optical signals as intensity ratios at two different wavelengths seems quite promising, for it would allow for a built-in correction for environmental effects. Until now, examples of fluorescent probes based on the ratiometric detection of gold ions have been inadequate, due to the absence of effective strategies and guidelines for designing ratiometric fluorescent molecules. ${ }^{5 a, 6 a, 8 b}$ In a recent contribution, we introduced a new strategy for ratiometrically sensing gold ions by exploiting the catalytic behaviour of gold ions to transform a highly conjugated probe structure into a non-conjugated one, by which the presence of gold species became detectable as an emission ratio of two distinct wavelengths. ${ }^{5 a}$ However, crosssensitivity towards mercury(II) ions is still a challenge to be addressed. Other examples of ratiometric gold ion probes available in recent literature are extensions of intensity-based sensors that draw upon a principle of fluorescence resonance energy transfer to achieve ratiometric response. ${ }^{8}$

It is a well-known fact that the extent of $\pi$-conjugation within the fluorophore-chromophore structure exerts a dramatic effect on the frontier orbital energy levels of the molecules. With the conjugation of fluorescent dye the energy difference between the orbitals decreases, which often results in a redshift of absorption and emission wavelengths.

Based on these considerations, we designed and constructed BOD-Z-EN by integrating a $Z$-enynol motif into a BODIPY-based fluorophore scaffold, with the expectation of generating a highly $\pi$-conjugated BODIPY derivative emitting at a wavelength distinctly longer than its unmodified scaffold (Scheme 1). We selected a BODIPY-based fluorophore as the signal reporter for not only its outstanding photo-physical features, but also its easy chemical modification. ${ }^{9}$ In the presence of gold species, as reported in the literature, substituted $Z$-enynols can efficiently cyclize to their corresponding furan derivatives. ${ }^{10}$

We envisioned that an intramolecular cyclisation triggered by gold ions could break the $\pi$-conjugation and generate a new 


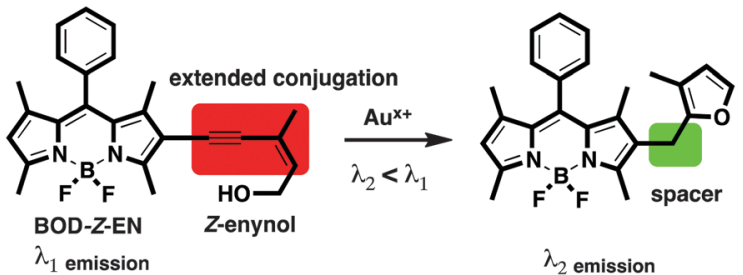

Scheme 1 The strategy for ratiometric sensing

BODIPY structure without that conjugation. We thought that the structural modification of the fluorescent probe would eventually yield a significant blue-shift in the fluorophore's emission wavelength, which would thus enable us to recognise the presence of gold species as a ratio of two distinct wave-lengths, by following the chief principle of ratiometric sensing (Scheme 1).

The fluorescent probe BOD-Z-EN was prepared by way of a straightforward synthetic pathway, as outlined in Scheme 2. The monoiodo derivative of BODIPY (BODIPY-I) prepared individually was coupled with $Z$-enynol [(Z)-3-methylpent-2-en-4-yn-1-ol] according to a Sonogashira coupling protocol in order to induce the desired probe structure in a moderate yield. ${ }^{11}$ Following chromatographic purification, the identity of the title compound was clearly confirmed by analytical data collected with nuclear magnetic resonance (NMR) spectroscopy and mass spectrometry. ${ }^{12}$ Using the synthetic route we prepared BOD-E-EN, the $E$-isomer of the probe, in order to elucidate the mechanism of gold ion detection.

With both compounds in hand, we first investigated the spectral properties of BOD-Z-EN and its response to a range of metal ions in a solution buffered to physiological $\mathrm{pH}(0.1 \mathrm{M}$ phosphate buffer/EtOH (pH 7.0, v/v, 7:3)).

We commenced spectral investigation by screening the optical behaviour of the probe in response to the addition of gold ions. In the absence of any analyte species, BOD-Z-EN displayed a single absorption band at $532 \mathrm{~nm}$ (Fig. 1a). Meanwhile, in the fluorescence spectrum of BOD-Z-EN, collected upon excitation at $460 \mathrm{~nm}$, a long wavelength emission band at $575 \mathrm{~nm}$ was clearly observed. As expected, upon adding $\mathrm{AuCl}_{3}$ (10 equiv.), we observed a new emission band at $512 \mathrm{~nm}$, with a sharp, concomitant decrease in emission band intensity at $575 \mathrm{~nm}$ (Fig. 1b).

The probe's response to $\mathrm{AuCl}_{3}$ was clearly visible to the naked eye; in the presence of gold species, the probe solution's

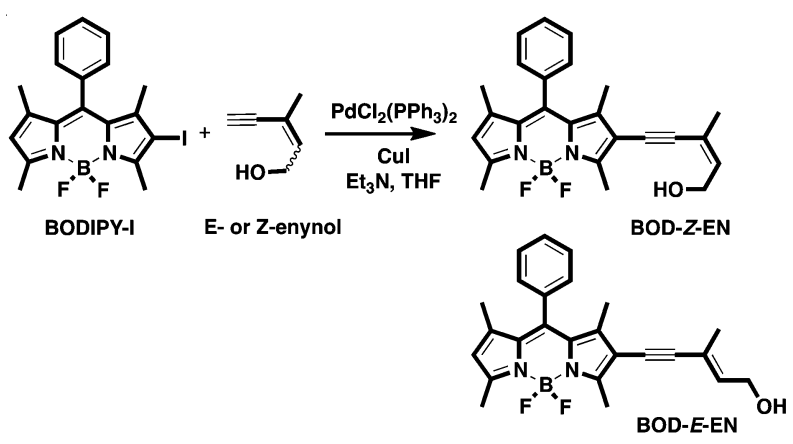

Scheme 2 Synthesis of BOD-Z-EN and BOD-E-EN.
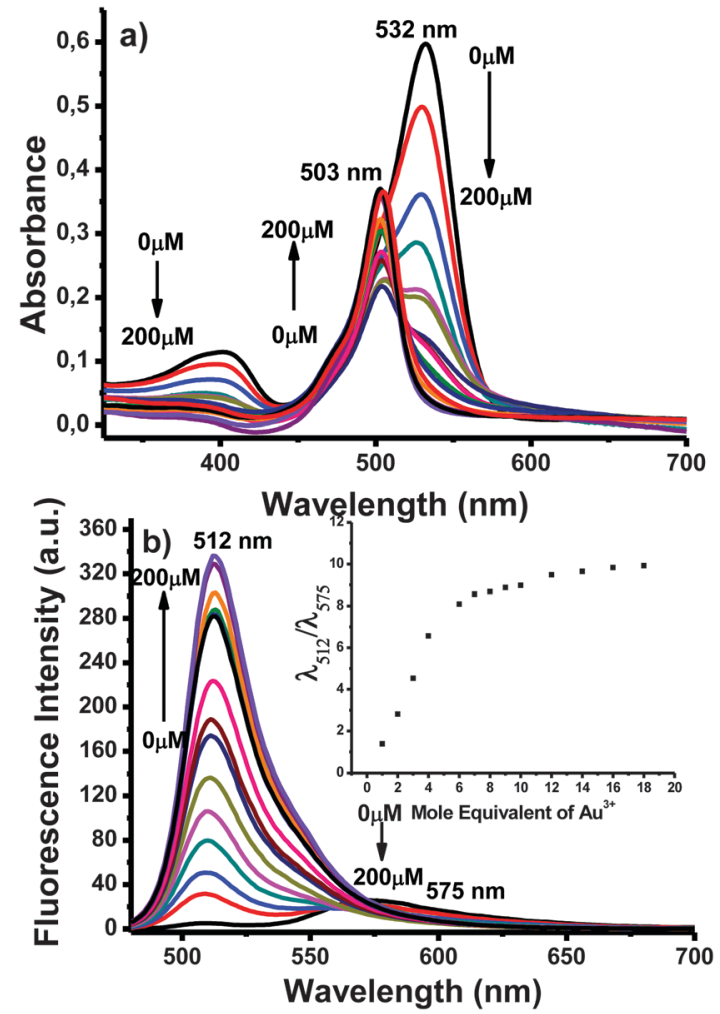

Fig. 1 (a) Absorbance and (b) fluorescence titration spectra of BOD-Z-EN $(10 \mu \mathrm{M})+\mathrm{Au}^{3+}(1$ to $200 \mu \mathrm{M}), 0.1$ to 20 equiv.) in $0.1 \mathrm{M}$ phosphate buffer/ EtOH (pH 7.0, v/v, 7: 3). Inset: Calibration curve.

orange emission became distinctly green, which we attributed to a structural modification of the dye structure (Scheme 1). A new green emissive compound, as monitored on a thin-layer chromatography plate, was additional clear evidence of the formation of a non-conjugated core BODIPY derivative (Fig. S11, ESI $\dagger$ ). Following chromatographic purification, the structure of the new BODIPY derivative was confirmed by NMR spectroscopy and high-resolution mass spectrometry (ESI-TOF) as BOD-FUR (quantum yield; $\Phi_{\mathrm{F}}=0.90$ ), the intramolecular cyclisation product of BOD-Z-EN $\left(\Phi_{\mathrm{F}}=0.05\right){ }^{12}$

Our investigation continued with the systematic addition of gold ions to the probe solution. Upon adding $\mathrm{Au}^{3+}$ ( $0-10$ equiv.), we observed the absorption band at $532 \mathrm{~nm}$ decrease gradually, with a concomitant linear increase of a new absorbance band at $503 \mathrm{~nm}$ (Fig. 1a). A similar trend occurred in fluorescence emission behaviour; with an increased concentration of $\mathrm{Au}^{3+}$ across a wide concentration range, fluorescence emission intensity at $512 \mathrm{~nm}$ increased linearly (Fig. 1b). The response of BOD-Z-EN to $\mathrm{Au}^{3+}$ (e.g., 1 equiv. of $\mathrm{AuCl}_{3}$ ) was exceptionally fast $(<30 \mathrm{~s})$, and within a couple of minutes, emission intensity (>65-fold) became completely saturated (Fig. S9, ESI $\dagger$ ). An 80 -fold enhancement in emission ratio occurred when 10 equiv. of gold was introduced. Under optimum sensing conditions, the detection limit of BOD-Z-EN for detecting $\mathrm{Au}^{3+}$ was $293 \mathrm{nM}$, based on the signal-to-noise ratio $(\mathrm{S} / \mathrm{N}=3)$ (Fig. S1, ESI $\dagger$ ).

The metal ion selectivity test for BOD-Z-EN resulted in no obvious spectral changes for competing alkynophilic metal 


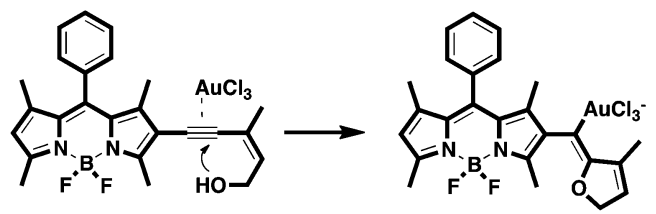

BOD-Z-EN cycloisomerization

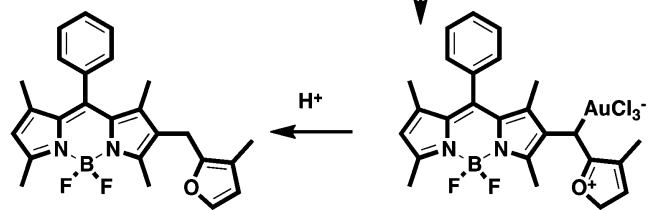

BOD-FUR

Scheme 3 Proposed mechanism for gold ion catalysed intramolecular cyclisation.

species, including $\mathrm{Ag}^{+}, \mathrm{Ni}^{2+}, \mathrm{Pd}^{2+}, \mathrm{Hg}^{2+}, \mathrm{Cu}^{2+}$, and other metal species such as $\mathrm{Mg}^{2+}, \mathrm{Mn}^{2+}, \mathrm{Pb}^{2+}, \mathrm{Zn}^{2+}, \mathrm{Cd}^{2+}, \mathrm{Fe}^{3+}, \mathrm{K}^{+}, \mathrm{Li}^{+}, \mathrm{Ba}^{2+}$, and $\mathrm{Ca}^{2+}$. Only the addition of $\mathrm{Au}^{3+}$ and, to a lesser extent the addition of $\mathrm{Au}^{+}$resulted in an increase of fluorescence at $512 \mathrm{~nm}$, which obviously implied the high selectivity of BOD-Z-EN to gold ions (Fig. S6, ESI $\dagger$ ). Remarkably, other metal ions did not interfere with the detection of gold ions, and the spectral response induced by $\mathrm{Au}^{3+}$ ions remained unaffected in the presence of any of those metal species. Such results indicate that BOD-Z-EN can properly detect $\mathrm{Au}^{3+}$ ions in mixtures with other related species. ${ }^{12}$

Analogous to reports in the literature, ${ }^{10}$ we propose that the sensing mechanism occurs when $\mathrm{Au}^{3+}$ activates the triple bond and the subsequent intramolecular exo-dig cyclisation of hydroxyl group to the triple bond, which, in forming a gold intermediate and a rapid isomerisation and protonolysis pathway, affords the BODIPY-furan structure (BOD-FUR) (Scheme 3).

In establishing the most efficient conditions for operation, BOD-Z-EN in the absence of $\mathrm{Au}^{3+}$ was quite stable, even in strong acidic and basic conditions. Likewise, the response of BOD-Z-EN to the addition of $\mathrm{Au}^{3+}$ ions remained unaffected by altering the $\mathrm{pH}$ of the sensing media (Fig. S4, ESI $\dagger$ ). As such, BOD-Z-EN operates efficiently over a wide $\mathrm{pH}$ range ( $\mathrm{pH}$ 2-12), especially in physiological conditions $(\mathrm{pH} 7.4)$, which fulfils a basic requirement for cell bioimaging.

In sharp contrast to BOD-Z-EN, the $E$-stereoisomer of the probe, BOD-E-EN, was inert to gold, as well as other metal species, despite being in identical sensing conditions. Consistent with the proposed mechanism and in agreement with reports in the literature, adding $\mathrm{Au}^{3+}$ did not alter the emission pattern of BOD-E-EN, thereby indicating the sensing process's high stereoselectivity (Fig. S10, ESI†).

Relying on the promising photochemical and physical properties of BOD-Z-EN, including its rapid response time, unique gold ion specificity, exceptionally low detection limit, and high fold ratiometric change, among other qualities, we next evaluated its potential for tracking $\mathrm{Au}^{3+}$ ions in living cells. To that end, A549 human lung adenocarcinoma cells were incubated at $37{ }^{\circ} \mathrm{C}$ first with BOD-Z-EN $(5.0 \mu \mathrm{M})$ for $20 \mathrm{~min}$,

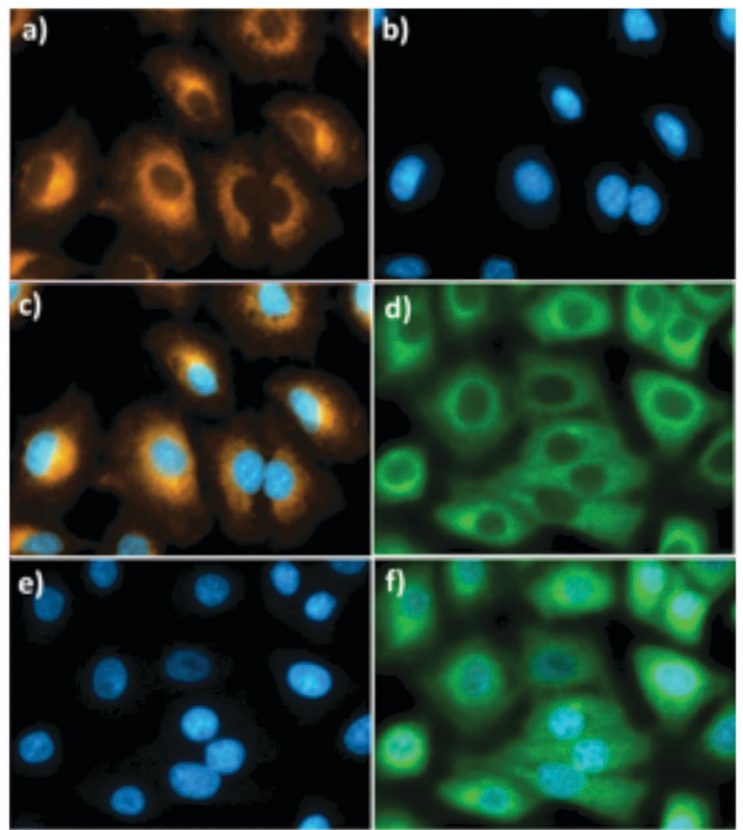

Fig. 2 Fluorescence images of human lung adenocarcinoma cells (A549). (a) Fluorescence image of A549 cells treated with only BOD-Z-EN (5 $\mu$ M); (b and e) fluorescence image of cells treated with DAPI (control); (d) fluorescence image of cells treated with BOD-Z-EN $(5 \mu \mathrm{M})$ and $\mathrm{Au}^{3+}(10 \mu \mathrm{M})$; ( $c$ and $\left.\mathrm{f}\right)$ merged images of frames ( $\mathrm{a}$ and $\left.\mathrm{b}\right)$ and ( $\mathrm{d}$ and $\mathrm{e}$ ) $\left(\lambda_{\text {ex }}=460 \mathrm{~nm}\right)$.

followed by incubation with $\mathrm{Au}^{3+}(10 \mu \mathrm{M})$ for another $20 \mathrm{~min}$. Using fluorescence microscopy, we could clearly monitor the ratiometric sensing behaviour of the probe toward $\mathrm{Au}^{3+}$ in the cells (Fig. 2). Consistent with results observed in the solution, following incubation with $\mathrm{Au}^{3+}$ the orange emissive cells immediately turned green, thereby unambiguously showing that BOD-Z-EN is cell-membrane permeable and has great potential for use in imaging $\mathrm{Au}^{3+}$ in living cells. Moreover, there were no indications of cell damage. Cells were intact and showed healthy spread and adherent morphology throughout the cell imaging process. The potential cytotoxicity of the probe was evaluated using a standard MTT assay with A549 cell line. The cellular viability was estimated to be $100 \%$ after $24 \mathrm{~h}$, which showed that the probe $(<5 \mu \mathrm{M})$ has no cytotoxicity (Fig. S2, ESI $\dagger$ ).

In sum, we devised a fluorescent probe that shows a ratiometric fluorescence response to gold ion species with high sensitivity and selectivity over other metal ion species. The fluorescent probe is built upon a BODIPY fluorophore scaffold that uses a highly novel reactive unit (e.g., Z-enynol) for $\mathrm{Au}^{3+}$ ions. After structural modification triggered by gold ions-namely, an intramolecular cyclisation - the high wavelength-emitting conjugated probe structure transformed into a non-conjugated, low wavelength-emitting structure, thereby allowing us to recognise gold ions as a ratio of distinct emission wavelengths. Apart from the rapid $(<30 \mathrm{~s})$, sensitive ( $293 \mathrm{nM})$, and highly specific response to gold species in the solution, the probe proved highly successful in imaging gold ions in living cells.

We thank Izmir Institute of Technology (IZTECH) and TUBTAK (113Z601) for financial support and Izmir Institute 
of Technology, Biotechnology and Bioengineering Research and Application Centre for fluorescence imaging facilities.

\section{Notes and references}

1 (a) B. Alcaide and P. Almendros, Acc. Chem. Res., 2014, 47, 939-952; (b) I. Braun, A. M. Asiri and A. S. K. Hashmi, ACS Catal., 2013, 3, 1902-1907; (c) N. Krause and C. Winter, Chem. Rev., 2011, 111, 1994-2009; (d) A. Arcadi, Chem. Rev., 2008, 108, 3266-3325; (e) A. S. K. Hashmi and M. Rudolph, Chem. Soc. Rev., 2008, 37, 1766-1775; $(f)$ Z. Li, C. Brouwer and C. He, Chem. Rev., 2008, 108, 3239-3265.

2 (a) C. M. Goodman, C. D. McCusker, T. Yilmaz and V. M. Rotello, Bioconjugate Chem., 2004, 15, 897-900; (b) A. Habib and M. Tabata, J. Inorg. Biochem., 2004, 98, 1696-1702; (c) W. D. Block and E. L. Knapp, J. Pharmacol. Exp. Ther., 1945, 83, 275-278.

3 (a) S. Singha, D. Kim, H. Seo, S. W. Cho and K. H. Ahn, Chem. Soc. Rev., 2015, 44, 4367-4399; (b) J. F. Zhang, Y. Zhou, J. Yoon and J. S. Kim, Chem. Soc. Rev., 2011, 40, 3416-3429.

4 (a) M. Emrullahoğlu, E. Karakuş and M. Üçüncü, Analyst, 2013, 138, 3638-3641; (b) L. Yuan, W. Lin, Y. Yang and J. Song, Chem. Commun., 2011, 47, 4703-4705; (c) O. A. Egorova, H. Seo, A. Chatterjee and K. H. Ahn, Org. Lett., 2010, 12, 401-403; (d) M. J. Jou, X. Chen, K. M. K. Swamy, H. N. Kim, H.-J. Kim, S. G. Lee and J. Yoon, Chem. Commun., 2009, 7218-7220; (e) Y. K. Yang, S. Lee and J. Tae, Org. Lett., 2009, 11, 5610-5613.

5 (a) M. Üçüncü, E. Karakuș and M. Emrullahoğlu, Chem. - Eur. J., 2015, 21, 13201-13205; (b) C. Cantürk, M. Üçüncü and M. Emrullahoğlu, RSC Adv., 2015, 5, 30522-30525; (c) E. Karakuş, M. Üçüncü and M. Emrullahoğlu, Chem. Commun., 2014, 50, 1119-1121; (d) M. Üçüncü and M. Emrullahoğlu, Chem. Commun., 2014, 50, 5884-5886; (e) J.-B. Wang,
Q.-Q. Wu, Y.-Z. Min, Y.-Z. Liu and Q.-H. Song, Chem. Commun., 2012, 48, 744-746; $(f)$ M. Üçüncü, E. Karakuș and M. Emrullahoğlu, New J. Chem., 2015, 39, 8337-8341; $(g)$ E. Karakuş, G. Cakan-Akdogan and M. Emrullahoğlu, Anal. Methods, 2015, 7, 8004-8008.

6 (a) H. Seo, M. E. Jun, O. A. Egorova, K. H. Lee, K. T. Kim and K. H. Ahn, Org. Lett., 2012, 14, 5062-5065; (b) N. Y. Patil, V. S. Shinde, M. S. Thakare, P. H. Kumar, P. R. Bangal, A. K. Barui and C. R. Patra, Chem. Commun., 2012, 48, 11229-11231; (c) S. Kambam, B. Wang, F. Wang, Y. Wang, H. Chen, J. Yin and X. Chen, Sens. Actuators, B, 2015, 209, 1005-1010.

7 (a) M. Dong, Y.-W. Wang and Y. Peng, Org. Lett., 2010, 12, 5310-5313; (b) J. Y. Choi, G.-H. Kim, Z. Guo, H. Y. Lee, K. M. K. Swamy, J. Pai, S. Shin, I. Shin and J. Yoon, Biosens. Bioelectron., 2013, 49, 438-441.

8 (a) X. Cao, W. Lin and Y. Ding, Chem. - Eur. J., 2011, 17, 9066-9069; (b) H. Seo, M. E. Jun, K. Ranganathan, K.-H. Lee, K.-T. Kim, W. Lim, Y. M. Rhee and K. H. Ahn, Org. Lett., 2014, 16, 1374-1377.

9 (a) N. Boens, V. Leen and W. Dehaen, Chem. Soc. Rev., 2012, 41, 1130-1172; (b) R. Ziessel, G. Ulrich and A. Harriman, New J. Chem., 2007, 31, 496-501; (c) A. Loudet and K. Burgess, Chem. Rev., 2007, 107, 4891-4932; (d) G. Ulrich, R. Ziessel and A. Harriman, Angew. Chem., Int. Ed., 2008, 47, 1184-1201.

10 (a) A. S. K. Hashmi, L. Schwarz, J.-H. Choi and T. M. Frost, Angew. Chem., Int. Ed., 2000, 39, 2285-2288; (b) Y. Liu, F. Song, Z. Song, M. Liu and B. Yan, Org. Lett., 2005, 7, 5409-5412; (c) X. Du, F. Song, Y. Lu, H. Chen and Y. Liu, Tetrahedron, 2009, 65, 1839-1845; (d) C. H. Oh, H. J. Yi and K. H. Li, Bull. Korean Chem. Soc., 2010, 31, 683-688.

11 M. Üçüncü, E. Karakuş, M. Kuş, G. E. Akpınar, Ö. Aksın-Artok, N. Krause, S. Karaca, N. Elmacı and L. Artok, J. Org. Chem., 2011, 76, 5959-5971.

12 See ESI $\dagger$. 